\title{
Capital Enrichment, Innovation Capability and Environmental Pollution Effect: Evidence from China's Manufacturing Industry
}

\author{
Fengju $\mathrm{Xu}^{*}$, Lina $\mathrm{Ma}^{*}$, Xiaoying $\mathrm{Li}^{* * \dagger} \uparrow$ and Najaf Iqbal*** \\ *Wuhan University of Technology, Hubei, Wuhan, 430070, China \\ **Changjiang Polytechnic, Hubei, Wuhan, 430070, China \\ ***Hunan University of Arts and Science, Hunan, Changde, 415000, China \\ $†$ Corresponding author: Xiaoying Li; 603700103@qq.com
}

\author{
Nat. Env. \& Poll. Tech. \\ Website: www.neptjournal.com \\ Received: 12-02-2020 \\ Revised: $10-04-2020$ \\ Accepted: 10-07-2020 \\ Key Words: \\ Chinese manufacturing \\ industry \\ Capital enrichment \\ Innovation capability \\ Environmental pollution
}

\begin{abstract}
In recent years, the issue of environmental pollution caused by the manufacturing industry has been widely criticized. To explore the relationship between capital enrichment and environmental pollution, the mediating effect model was constructed by using the panel data of 28 sub-sectors of China's manufacturing industry from 2011 to 2017 . Results show that the phenomenon of capital enrichment is mainly concentrated in industries with high-profit margins, intensive technology, national policy support, and resource or national monopolistic positions. Both capital enrichment and innovation capability have a promotion effect on inhibiting environmental pollution, but with the decline of innovation capability, the effect of capital enrichment on pollution weakens. Innovation capability plays a mediating role, which leads to the mechanism of capital enrichment $\rightarrow$ innovation capability $\rightarrow$ environmental pollution. The impact of capital enrichment on environmental pollution under different levels of innovation capability is heterogeneous, and the effect is stronger in high-tech industries.
\end{abstract}

\section{INTRODUCTION}

Since the national reforms and opening-up policies of 1978 , the demographic dividends and the low-cost advantages of primary production factors have resulted in the rapid development of China's manufacturing industry. The world-class manufacturing centres are formed in the regions of Bohai Rim, the Pearl River Delta, and the Yangtze River Delta in China. In a matter of three decades, China has been developed into the world's largest manufacturing factory, leading to the rapid growth of China's economy. However, for a long time, the development of China's manufacturing industry has relied heavily on the cheap labour, land and other natural resources, and a high tolerance for environmental pollution. It is an extensive growth pattern that relies heavily on inputs, cost-competitive strategies, high energy consumption resulting in serious environmental pollution issues and low resource-utilization. The innovation has remained far slower than the rate of environmental degradation resulting in the practical dilemma of high levels of pollution.

Given the background of constructing the spatial patterns of saving resources and protecting the environment, scholars have begun to pay attention to the relationship between capital enrichment and pollution caused by the manufacturing industry. However, the existing literature mainly focuses on the impact of FDI, human capital, and financial capital on the environment (Al-Mulali et al. 2015), without reaching any consistent conclusions. The systematic analysis of the internal interaction mechanism between capital enrichment and environmental pollution is far less addressed. Another interesting variable is innovation ability which is also under-discussed in the context of rising productivity levels, capital accumulation and pollution effects. Only on the premise of continuous improvement of innovation capability, it plays a role in environmental pollution (Schot et al. 2018), because capital is the material basis for technology innovation. When capital enrichment is at a high level, its support for innovation activities is strong, resulting in the spillover effects for green technologies. The phenomenon of green production can reduce and ultimately eliminate the negative effects on the environment and promote the manufacturing industry to realize the economic and ecological benefits of the resources.

Capital is the material guarantee for innovation capability largely, and innovation capability is the most important way to reduce environmental pollution (Zailani et al. 2015). However, ignoring this important nexus, existing studies focus on the single perspective of capital and pollution or innovation and pollution, and rarely integrate capital and innovation capability into one framework to analyze their impact on environmental pollution. The capital, innovation, and environmental pollution may form a complete framework, but 
the existing research ignores the interaction between these variables and lacks the discussion on the mediating effect of innovation capability. This study builds the logical framework of capital enrichment $\rightarrow$ innovation capability $\rightarrow$ environmental pollution and analyzes the internal mechanism. It also investigates the pollution effects resulting from capital under different levels of innovation capability.

\section{PAST STUDIES AND HYPOTHESIS DEVELOPMENT}

On the relationship between capital and pollution, existing scholars mainly focus on the perspective of foreign capital and human capital. The foreign capital entering the Chinese market brought green production technology, scientific management experience and global unified environmental standards, resulting in the positive environmental effects. Industries with higher levels of foreign investment have fewer pollutant emissions. The above-mentioned studies can be described as the phenomenon of pollution halo. Liang (2014) also supported the conclusion that foreign capital could increase resource efficiency through technology diffusion and reducing sulfur dioxide emissions. The human capital perspective determines the ability of a country to absorb and diffuse technology (Xu et al. 2020), which is more likely to support enterprises to use new technologies for promoting the green environmental production.

The relationship between the development of manufacturing industry, resource consumption, and pollution emissions in China has recently gained the attention of eminent scholars. The environment has been incorporated into the economic growth model as a factor of production. Factor endowment, especially the material capital determines the comparative advantage of polluting industries. Rubashkina et al. (2014) found that the influence of manufacturing with different endowment advantages on environmental pollution is heterogeneous. Capital enrichment weakens the carbon emission intensity and causes a change from negative to positive environmental effects. With the development of China's financial market, companies can absorb more capitals (Frankel et al. 1999), and promote the inhibition of environmental pollution by using clean energy or technology. So, the following hypothesis is proposed.

\section{Hypothesis 1: Capital Enrichment Reduces the Degree of Environmental Pollution}

According to Schumpeter's augmentation model and the Neo-Classical growth model, innovation plays the essential impact on capital enrichment (Xu et al. 2020). Insufficient capital may reduce the probability of innovative projects and inhibit innovation output. In China's financial environment where the capital supply is not completely market-oriented, the innovation capability of enterprises is greatly constrained by this supply shortage. Relying solely on their internal resources will not be enough to meet the fast-growing market requirements where the cost of innovation is fairly high. With an increase in innovation capability and favourable national policies, more market potential is released and the support of capital resources for innovation is strengthened (Xiong et al. 2020). The source of the innovation capital gradually shifts to the diversified sources including the capital market, government agencies and its affiliates (Du et al. 2020). A high level of innovation capability encourages firms to invest more capital in innovation activities, producing cyclic effects. Rodrigo-Alarcón et al. (2017) also emphasized the role of social capital in promoting innovation capability.

There are a few studies available in the literature on the relationship between innovation capability and environmental pollution, and most of these present the perspective of technological progress. The positive and promotional effect is controversial (Fagerberg et al. 2013, Schmidt et al. 2019). As the emission and pollution reduction caused by the innovation is realized through stimulating the innovation compensation effect which is the core factor for improving market competitiveness. The innovation is the main reason for reducing the intensity of energy consumption and it shows a tendency of energy conservation. Zailani et al. (2015) took the automobile manufacturing industry as research samples and found that the innovation and application of green technology can significantly improve environmental performance. However, some believe that the inhibitory effect of innovation capability on environmental pollution is limited. Since the total amount of environmental pollution is increasing (Schmidt et al. 2019), the sustainable development of the whole society should be achieved through innovative transformation (Fagerberg et al. 2013, Schot et al. 2018).

From the practice of China's manufacturing industry, innovation-driven is the breakthrough for its sustainable development and also the key to moving it towards the highend of the global value chain. It means that a large number of traditional workers may gradually be replaced by a small number of modern knowledge-based workers. With the improvement of capital in the manufacturing industry, the intensity of investment in innovation has been continuously rising. Enterprises have effectively reduced the emissions of environmental pollution by adopting advanced pollution control technologies, green production, and environmental management measures. Therefore, this study argues that the innovation capability of the manufacturing industry can cause a reduction in environmental pollution, and the innovation capability may play a mediating role between the relationship 
of capital enrichment and environmental pollution. So the following hypothesis is proposed.

\section{Hypothesis 2: Innovation Capability Plays a Mediating Role Between the Relationship of Capital Enrichment and Environmental Pollution}

\section{Methodology}

Modelling: To investigate the impact of the manufacturing industry's capital enrichment on environmental pollution, the following basic model is constructed.

$$
E P_{i, t}=\beta_{0}+\beta_{1} C E_{i, t}+\text { Controt }_{i, t}+\varepsilon_{i, t}
$$

Where $E P_{i, t}$ is the environmental pollution of the $i^{\text {th }}$ manufacturing industry at time $t, C E$ is the capital enrichment, $\beta$ is a constant term, and $\varepsilon$ is the random error term. Adopted from Abbasi et al. (2016) and Li et al. (2020), the following variables are controlled: human capital intensity (Human), degree of openness (Open), R\&D intensity (RD), fixed asset investment (Asset), and firm-scale (Size). To examine the hypothesis proposed above, innovation capability is first included in the equation then capital enrichment is introduced to construct a new equation. To examine the channel effect, the interactive item $C E^{*} I C$ is introduced and the centralization method is used to avoid multicollinearity issues possibly caused by introducing the interaction term (Dalal et al. 2012).

$$
\begin{gathered}
E P_{i, t}=\beta_{0}+\beta_{1} I C_{i, t}+\text { Controls }_{i, t}+\varepsilon_{i, t} \\
E P_{i, t}=\beta_{0}+\beta_{1} C E_{i, t}+\beta_{2} I C_{i, t}+\Sigma \text { Control } \varepsilon_{i, t} \\
E P_{i, t}=\beta_{0}+\beta_{1} C E_{i, t}+\beta_{2} I C_{i, t}+\beta_{3} C E_{i, t} * I C_{i, t}+\Sigma \text { Control }+\varepsilon_{i, t}
\end{gathered}
$$

To test the mediating effect of innovation capability on the relationship between capital enrichment and RP, the following model is constructed by adopting from the mediating effect test method.

$$
\begin{gathered}
E P_{i, t}=\beta_{0}+\beta_{1} C E_{i, t}+\Sigma \text { Control }+\varepsilon_{i, t} \\
I C_{i, t}=\gamma_{0}+\gamma_{1} C E_{i, t}+\Sigma \text { Control }+\varepsilon_{i, t} \\
E P_{i, t}=\mu_{0}+\mu_{1} C E_{i, t}+\mu_{2} I C_{i, t}+\Sigma \text { Control }+\varepsilon_{i, t}
\end{gathered}
$$

Where $\beta_{1}$ is the total effect of capital enrichment on environmental pollution, $\mu_{1}$ is the direct effect of capital enrichment on environmental pollution, $\gamma_{1} \mu_{2}$ is the mediating effect and its relative value is the ratio of the mediating effect to the total effect.

Data sources: Consistent with the 2012 industry classification standard of the China Securities Regulatory Commission (CSRC), this study finally selects 28 manufacturing industry segments.

The sample period ranges from 2011 to 2017 and missing values are calculated (included) by linear interpolation. All data are from the National Bureau of Statistics, the China Statistical Yearbook, China Energy Statistical Yearbook, China Environmental Statistical Yearbook, and the China Science and Technology Statistical Yearbook.

\section{Variables: Capital Enrichment of manufacturing industry:} The capital enrichment results from a constant accumulation of the capital inflows. This study analyzes the capital distribution in China's manufacturing industry to determine whether there is an objective phenomenon of capital enrichment or not. The average annual capital distribution of 28 manufacturing segments from 2011 to 2017 is shown in Fig. 1.

As evident from Fig. 1, it shows that the total capital of certain industries exceeds the industry median irrespective of the benchmark chosen (total capital of the industry, the capital owned by a single enterprise/the capital occupied by the industrial added value of RMB 100 million). Therefore, the phenomenon of capital enrichment exists objectively, which is the result of excessive capital inflows to an industry.

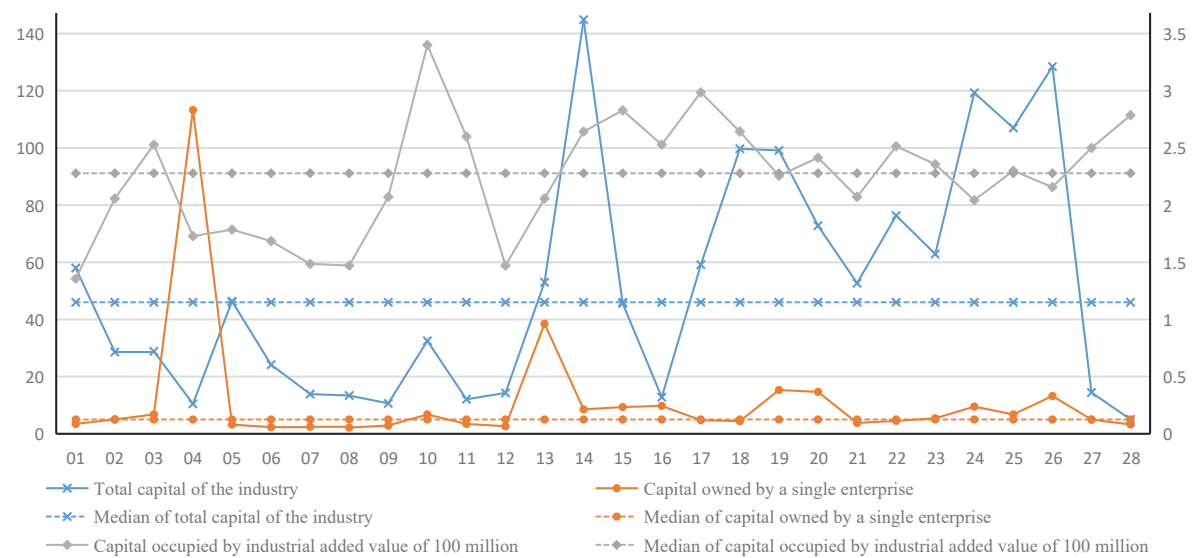

Fig. 1: Average capital distribution of 28 manufacturing industries in 2011-2017.

Note: The code means 28 sub-sectors of China's manufacturing industry. 
It reflects the distribution of capital in different regions or industries and can create new value in the process of capital flow to achieve the continuous growth of capital enrichment. The most intuitive manifestation of capital enrichment is the increase in the total capital amount. According to the different sources of investment, i.e., the state, collective, corporate, individuals, Hong Kong, Macao, Taiwan, and foreign capital, this study defines the above total capital as capital enrichment.

Innovation capability of manufacturing industry: The formation of innovation capability is the result of the comprehensive contribution of many factors and the existing literature presents numerous related studies. Referring to Connie (2014) and Roper et al. (2015), the following comprehensive evaluation index system of innovation capability is constructed by combining with characteristics of the manufacturing industry and influencing factors of innovation capability, as given in Table 1 . The entropy weight method is adopted to calculate the weight of each index.

Environmental pollution of manufacturing industry: As evident from the existing literature, there is no consistent standard for the measurement of environmental pollution. It is mainly measured by all or a single index of wastewater, waste gas, and solid wastes (Kolkis 2019, Li et al. 2019). Some scholars use the entropy weight method to combine the following indicators into the composite index of environmental pollution, i.e., wastewater, chemical oxygen demand, ammonia nitrogen, sulfur dioxide, and solid waste discharge. Since the National Bureau of Statistics no longer publishes the wastewater and waste gas wastes in different industries after 2012, this study uses solid waste discharge per unit of production value as the proxy variable for environmental pollution.

\section{RESULTS AND DISCUSSION}

\section{Scatter Plot}

To verify the hypothesis proposed in this study initially, the scatter plot method is used to examine the relationship between the main variables. Fig. 2 shows the scatter plot of capital enrichment and environmental pollution, and capital enrichment and innovation capability. The capital enrichment has a negative impact on environmental pollution, and a positive impact on innovation capability, which is consistent with the main idea of this study. However, the transmission

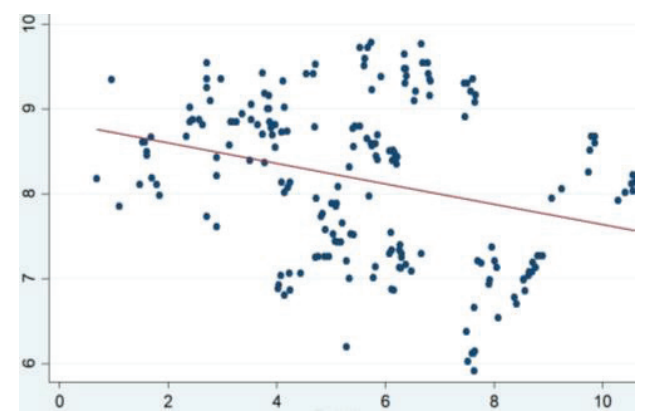

(a) Capital Enrichment and Environmental Pollution

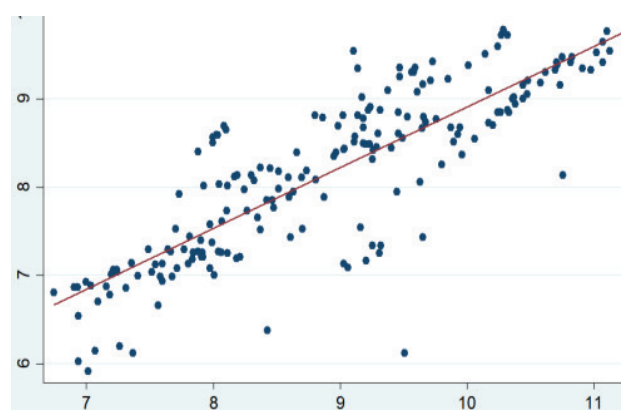

(b) Capital Enrichment and Innovation Capability

Fig. 2: Scatter plot between main variables.

Table 1: Evaluation index system of innovation capability in china's manufacturing industry.

\begin{tabular}{|lll|}
\hline First Class Index & Second Class Index & Third Class Index \\
\hline $\begin{array}{l}\text { Innovation resource } \\
\text { input }\end{array}$ & Human resource input & $\begin{array}{l}\text { Number of R\&D personnel, R\&D personnel full-time equivalent, and average number of employees } \\
\text { Financial resource input }\end{array}$ \\
$\begin{array}{l}\text { R\&D expenditure, investment intensity of R\&D expenditure, funding for new product development, } \\
\text { and the ratio of fixed assets equipment }\end{array}$ \\
$\begin{array}{l}\text { R\&novation implemen- } \\
\text { Ration capability }\end{array}$ & $\begin{array}{l}\text { Production \& marketing } \\
\text { capacity }\end{array}$ & $\begin{array}{l}\text { Marketing expense, expenditure on technology introduction, expenditure on digestion and ab- } \\
\text { sorption expenditure on purchasing domestic technology, and expenditure on technical renovation }\end{array}$ \\
Patent output & $\begin{array}{l}\text { Number of patent applications, invention patent applications proportion of utility model patents, } \\
\text { and patent applications / R\&D personnel }\end{array}$ \\
& Non-patent output & Main operating revenue, revenue of new products, total exports of new products, and total profit \\
\hline
\end{tabular}


Table 2: Basic regression results of capital enrichment, innovation capability and environmental pollution.

\begin{tabular}{|lllll|}
\hline Variable & Model $(1)$ & Model $(2)$ & Model $(3)$ & Model $(4)$ \\
\hline CE & $-3.601^{* * *}(0.406)$ & & $-2.194^{* * *}(0.392)$ & $-2.001^{* * *}(0.752)$ \\
IC & & $-1.595^{* * *}(0.146)$ & $-1.217^{* * *}(0.151)$ & $-1.062^{*}(0.595)$ \\
CE*IC & & & $-0.018^{* *}(0.070)$ \\
Human & & $-0.527^{* * *}(0.131)$ & $-0.519^{* * *}(0.121)$ & $0.518^{* * * *}(0.121)$ \\
Open & $-0.045(0.115)$ & $-2.075^{* * *}(0.716)$ & $-1.251^{*}(0.680)$ & $-1.258^{*}(0.702)$ \\
RD & $-3.169^{* * * *}(0.734)$ & $-0.112^{* *}(0.056)$ & $-0.126^{* *}(0.052)$ & $-0.132^{* * *}(0.052)$ \\
Asset & $-0.130^{* * *}(0.061)$ & $2.841^{* * *}(0.135)$ & $4.568^{* * *}(0.333)$ & $4.533^{* * *}(0.332)$ \\
Size & $4.952^{* * *}(0.382)$ & $-0.029^{*}(0.041)$ & $-0.010(0.038)$ & $0.002(0.037)$ \\
Constant & $0.043(0.044)$ & $-2.865^{* *}(1.137)$ & $-3.354^{* * *}(1.060)$ & $-4.617(5.144)$ \\
Obs & $-7.816^{* * *}(1.045)$ & 196 & 196 & 196 \\
$\mathrm{R}^{2}$ & 196 & 0.816 & 0.842 & 0.842 \\
\hline
\end{tabular}

Note: Robust standard errors in brackets; ${ }^{*} \mathrm{p}<0.1,{ }^{* *} \mathrm{p}<0.05,{ }^{* * *} \mathrm{p}<0.01$.

mechanism among capital enrichment, innovation capability and environmental pollution remains to be further tested.

\section{Transmission Mechanism Analysis}

It proposes that the capital enrichment of China's manufacturing industry not only directly affects environmental pollution but also indirectly through innovation capability. So, it explores the transmission mechanism among capital enrichment, innovation capability and environmental pollution by using a panel of China's manufacturing industry. The software used for the analysis is Stata15.0. The linear regression is initially performed on capital enrichment, innovation capability, and environmental pollution, and the interaction term between capital enrichment and innovation capability is also introduced. The centralized treatment method is used to reduce possible collinearity problems, and the results are shown in Table 2.

The model (1) in Table 2 shows the direct influence of capital enrichment on environmental pollution. The results show that capital enrichment and environmental pollution are negatively correlated at $1 \%$, with the coefficient of -3.601 , indicating that manufacturing capital enrichment can bring down the pollution effect. The main reason may be that the higher level of capital enrichment encourages enterprises to invest additional capital in green technology innovation, adopt cleaner energy, advanced manufacturing technology, and effectively manage the experience to reduce pollutant emissions. The results support hypothesis 1 proposed above. The model (2) presents the impact of innovation capability on environmental pollution. There is a significant negative correlation between these two variables at $1 \%$, indicating that the higher the level of innovation capability, the stronger the promotional effect on reducing pollution.

The transmission mechanism of capital enrichment affecting environmental pollution through innovation capability is analyzed. If it is right, in the regression model where environmental pollution is used as the explained variable, if innovation capability is removed, the effect of capital enrichment on environmental pollution should remain significant. After introducing innovation capability, the coefficients of

Table 3: Mediating effect of innovation capability.

\begin{tabular}{|llll|}
\hline \multirow{2}{*}{ Variable } & \multicolumn{2}{c|}{ Model (5) } & Model (6) \\
\cline { 2 - 4 } & EP & IC & EPdel (7) \\
\hline IC & $-3.601^{* * *}(0.406)$ & $1.156^{* * *}(0.169)$ & $-2.194^{* * *}(0.392)$ \\
Controls & & & $-1.217^{* * *}(0.151)$ \\
Obs & Yes & Yes & Yes \\
$\mathrm{R}^{2}$ & 196 & 196 & 196 \\
Sobel & 0.788 & 0.986 & 0.842 \\
\hline
\end{tabular}

Note: Robust standard errors in brackets; ${ }^{*} \mathrm{p}<0.1,{ }^{* *} \mathrm{p}<0.05,{ }^{* * * *} \mathrm{p}<0.01$. 
capital enrichment decrease fairly but both capital enrichment and innovation capability are significant at $1 \%$. By further introducing the interaction term $C E * I C$, its coefficient is -0.018 , but the significance of innovation capability significantly decreased from $1 \%$ to $10 \%$. It suggests that with the decline of innovation capability, the inhibitory effect of capital enrichment on environmental pollution becomes weak.

\section{Mediating Effect Analysis}

To further explore the role of innovation capability in the relationship between capital enrichment and environmental pollution, the empirical test is performed according to the mediating effect model. The results are shown in Table 3.

Results from the model (5) show that the coefficient of capital enrichment is -3.601 and significant at $1 \%$, demonstrating that capital enrichment has a promotional effect on reducing environmental pollution. In the model (6), the coefficient of innovation capability is 1.156 and significant at $1 \%$, showing that capital enrichment can improve the level of innovation capability. The main reason is that capital is the material basis for the implementation of innovation activities. The higher capital enrichment enables firms to have more capital for technical innovation, and then promote the spillover effect of technology. In the model (7), the coefficients of capital enrichment and innovation capability are both negative and significant at $1 \%$, indicating that innovation capability indeed plays a mediating role. Additionally, the $Z$ value in the Sobel test is 5.215 and significant at $1 \%$, showing that the mediating effect of innovation capability is significant. Its proportion in the total effect is $39.07 \%$, which proves the validity of hypothesis 2 .

\section{Robustness Test}

Considering that the annual data may fluctuate greatly, this study processes it three times and re-estimates the relationship between capital enrichment, environmental pollution and innovation capability. The results are shown in the Robust 1 in Table 4.

The capital enrichment of China's manufacturing industry has a negative effect on environmental pollution and a positive effect on innovation capability, both of which are significant. After adding capital enrichment and innovation capability at the same time, the coefficient of capital enrichment remains significant, but the negative effect on environmental pollution is decreased from -3.974 to -1.845 . The Z-value in the Sobel test is 6.348 and significant at $1 \%$, proving once again that innovation capability has the mediating effect.

Considering that the environmental pollution effect brought by capital enrichment may have hysteresis, this study re-estimates the model by using the one-period lagged values of the explained variable. The results are shown in the robust 2 in Table 4. Results reveal that innovation capability still plays a significant mediating role in the relationship between capital enrichment and environmental pollution, which proves the robustness of the above results.

\section{Further Analysis}

Due to a large number of China's manufacturing segments, the innovation capability and development priorities are different among sectors, which may reduce the practical significance of the results if they are not classified. Referring to OECD's classification criteria for the manufacturing industry, 28 segments are divided into the low-tech and high-tech industry by combining with their innovation capability. The results of the environmental pollution effect caused by capital enrichment under different innovation capability levels are shown in Table 5.

As revealed by the results, the impact of capital enrichment on environmental pollution in the low-tech industries is -2.357 at $1 \%$ significant level, and innovation capability plays a mediating effect on their relationship. By using the Sobel test method, it finds that the $Z$ value in the Sobel test is

Table 4: Mediating effect of innovation capability after shifting mean values.

\begin{tabular}{|lllll|}
\hline Variable & & EP & IC & EP \\
\hline \multirow{2}{*}{ Robust 1} & CE & $-3.974^{* * *}(0.430)$ & $1.129^{* * *}(0.151)$ & $-1.845^{* * *}(0.369)$ \\
& IC & & $-1.886^{* * *}(0.157)$ \\
& Sobel & $\mathrm{Z}=6.348$, the P-value is $0.000 ;$ Mediating Effect/Total Effect $=53.58 \%$ & $-1.388^{* * *}(0.399)$ \\
& L.CE & $-2.444^{* * *}(0.410)$ & $0.900^{* * *}(0.161)$ & $-1.174^{* * *}(0.179)$ \\
Robust 2 & IC & & $0.547^{* * *}(0.053)$ & $0.398^{* *}(0.154)$ \\
& Human & $-0.245^{*}(0.134)$ & \\
\hline
\end{tabular}

Note: Robust standard errors in brackets; ${ }^{*} \mathrm{p}<0.1,{ }^{* *} \mathrm{p}<0.05,{ }^{* * *} \mathrm{p}<0.01$. 
Table 5: Environmental pollution caused by capital enrichment under different levels of innovation capability.

\begin{tabular}{|c|c|c|c|c|c|c|}
\hline \multirow{2}{*}{ Variable } & \multicolumn{3}{|c|}{ Low-tech industry } & \multicolumn{3}{|c|}{ High-tech industry } \\
\hline & $\mathrm{EP}$ & $\mathrm{IC}$ & $\mathrm{EP}$ & $\mathrm{EP}$ & IC & $\mathrm{EP}$ \\
\hline $\mathrm{CE}$ & $-2.357^{* * * *}(0.476)$ & $0.624^{* * * *}(0.191)$ & $-1.739^{* * *}(0.455)$ & $-6.479^{* * *}(0.746)$ & $1.679^{* * * *}(0.284)$ & $-3.378^{* * * *}(0.730)$ \\
\hline IC & & & $-0.991^{* * *}(0.195)$ & & & $-1.847^{* * * *}(0.295)$ \\
\hline Controls & yes & yes & yes & yes & yes & yes \\
\hline $\mathrm{R}^{2}$ & 0.831 & 0.769 & 0.858 & 0.844 & 0.564 & 0.921 \\
\hline Sobel & \multicolumn{3}{|c|}{$Z=2.748$, Mediating Effect/Total Effect $=26.24 \%$} & \multicolumn{3}{|c|}{$Z=4.298$, Mediating Effect/Total Effect $=47.86 \%$} \\
\hline
\end{tabular}

Note: Robust standard errors in brackets; $* \mathrm{p}<0.1, * * \mathrm{p}<0.05, * * * \mathrm{p}<0.01$.

2.748 and significant at $1 \%$. The proportion of the mediating effect in the total effect is $26.24 \%$. However, the regression coefficients between capital enrichment and environmental pollution, and capital enrichment and innovation capability in the high-tech industry are -6.479 and 1.679 , respectively, both of which are significant at $1 \%$. The $Z$ value in the Sobel test is 4.298 and significant at $1 \%$. Compared with the low-tech industries, the mediating effect in the high tech-industries is $47.86 \%$ of the total effect. This finding indicates that the mediating effect of innovation capability is more significant in high-tech industries.

\section{CONCLUSIONS}

Based on the panel data of 28 sub-sectors of China's manufacturing industry from 2011 to 2017, this study explores the nexus between capital enrichment, innovation capability and environmental pollution by using the basic regression model and the mediating effect model. The main conclusions are as follows:

Firstly, the industries with higher levels of capital enrichment generally possess one or more of the following characteristics: higher-profit margins, technologyintensive, national policy support, and resource-based national monopoly industry. There is a significant negative correlation between capital enrichment and environmental pollution, showing that an increase in capital enrichment can reduce environmental pollution. Secondly, capital enrichment has a positive impact on innovation capability, while innovation capability has a negative impact on environmental pollution. The interaction effect of innovation capability between capital enrichment and environmental pollution is significantly negative, indicating that with the decline of innovation capability, the inhibitory effect of capital enrichment on environmental pollution becomes weak. Thirdly, the relationship between capital enrichment and environmental pollution is affected by innovation capability which plays a significant mediating effect. Fourthly, in both low-tech industries and high-tech manufacturing industries, the innovation capability has the mediating effect, and it is heterogeneity under different innovation capabilities.

\section{ACKNOWLEDGEMENT}

The study was supported by Grant from the China Social Science Foundation (15BJY065).

\section{REFERENCES}

Abbasi, F. and Riaz, K. 2016. $\mathrm{CO}_{2}$ emissions and financial development in an emerging economy: An augmented VAR approach. Energy Policy, 90(3): 102-114.

Al-Mulali, U., Ozturk, I. and Lean, H.H. 2015. The influence of economic growth, urbanization, trade openness, financial development, and renewable energy on pollution in Europe. Natural Hazards, 79(1): 621.

Connie, Z. 2014. The inner circle of technology innovation: A case study of two Chinese firms. Technological Forecasting \& Social Change, 82(2): 140-148.

Dalal, D.K. and Zickar, M.J. 2012. Some common myths about centering predictor variables in moderated multiple regression and polynomial regression. Organizational Research Methods, 15(47): 339-362.

Du, Y.C. and Wang, R.X. 2020. Impact of corporate governance ability on capital gains in mixed ownership enterprises. Transformations in Business \& Economics, 19(2): 92-113.

Fagerberg, J., Martin, B.R. and Andersen, E.S. 2013. Innovation Studies: Evolution and Future Challenges. Oxford University Press, Oxford.

Frankel, J.A. and Romer, D. 1999. Does trade cause growth? American Economic Review, 89(3): 379-399.

Kolkis, S. 2019. Benchmarking the sustainability of urban energy, water and environment systems and envisioning a cross-sectoral scenario for the future. Renewable and Sustainable Energy Reviews, 103(7): 529-545.

Li, M. and Wang, Q. 2020. Does industrial relocation alleviate environmental pollution? A mathematical economics analysis. Sustainability, 22(14): 4673-4698.

Li, Z., Wang, X., Li, J., Zhang, W., Liu, R., Song, Z., Huang, G. and Meng, L. 2019. The economic-environmental impacts of China's action plan for soil pollution control. Sustainability, 11(8): 2322-2334.

Liang, F.H. 2014. Does foreign direct investment harm the host country's environment? Evidence from China. International Finance Journal, 15(12): 1-28.

Rodrigo-Alarcón, J., García-Villaverde, P.M. and Ruiz-Ortega, M.J. 2017. From social capital to entrepreneurial orientation: The mediating role of dynamic capabilities. European Management Journal, 32(2): 1-15.

Roper, S. and Hewitt-Dundas, N. 2015. Knowledge stocks, knowledge flows and innovation: Evidence from matched patents and innovation panel data. Research Policy, 44(7): 1327-1340. 
Rubashkina, Y., Galeotti, M. and Verdolini, E. 2014. Environmental regulation and competitiveness: Empirical evidence on the Porter Hypothesis from European manufacturing sectors. Energy Policy, 61(2): 119-134.

Schmidt, T. and Sewerin, S. 2019. Measuring the temporal dynamics of policy mixes: An empirical analysis of renewable energy policy mixes' balance and design features in nine countries. Research Policy, 48(10): 1-13.

Schot, J. and Kanger, L. 2018. Deep transitions: Emergence, acceleration, stabilization and directionality. Research Policy, 47(6): 1045-1059.
Xiong, Z., Wang, P.J. and Zhao, Y. 2020. Re-innovation from failure, institutional environmental differences, and firm performance: Evidence from China. Amfiteatru Economic, 22(53): 197-219.

Xu, F.J., Ma, L.N. and Najaf, I. 2020. Interaction mechanism between sustainable innovation capability and capital stock: Based on PVAR model. Journal of Intelligent and Fuzzy Systems, 38(6): 7009-7025.

Zailani, S., Govindan, K. and Iranmanesh, M. 2015. Green innovation adoption in automotive supply chain: The Malaysian case. Journal of Cleaner Production, 108(19): 1115-1122. 